\title{
The Multi-Faith Religious Support Scale: Validation with a Sample of Muslim Women
}

Jeffrey P. Bjorck, Ph.D.

\author{
Audrey A. Maslim, Ph.D. \\ Graduate School of Psychology \\ Fuller Theological Seminary \\ Pasadena, CA
}

\begin{abstract}
The Religious Support Scale (RSS; Fiala, Bjorck, \& Gorsuch, 2002) includes Christian terminology (e.g., church, congregation), limiting its generalizability. We modified the RSS and assessed the reliability and validity of our new Multi-Faith Religious Support Scale (MFRSS) with 539 Muslim women in the United States. The MFRSS replicated the RSS's three-factor structure and subscale reliabilities. The three subscales respectively assess perceived support from religious peers (fellow adherents), from religious leaders, and from Allah. Moreover, even after controlling for social support, support from religious leaders and from Allah were both related to more life satisfaction. Support from Allah was also associated with less depression. Religious support's value among Muslim women is discussed, and the generalizability of the MFRSS is addressed.
\end{abstract}

Religious Support Among Muslim Women in the United States

Religiousness has frequently been linked with positive psychological functioning (see Koenig, McCullough, \& Larson, 2001, for review), though this relationship has commonly been tested only with crude measures. For example, until more recently, support from one's religious community was measured 
primarily by implying it from one-item church attendance measures (Bjorck \& Kim, 2009). Clearly, more sophisticated scales provide a better assessment of variance regarding any construct (Nunnally \& Bernstein, 1994). Religiousness deserves this level of inquiry, given the range of faith traditions and the multifaceted nature of religiousness within traditions (Hill \& Pargament, 2003); religious support is one construct that exemplifies this multidimensionality.

Fiala, Bjorck, and Gorsuch (2002) likened religious support to general social support, with the difference that religious support comes from one's God concept (if present) and/or from those who share one's faith. They developed the Religious Support Scale (RSS) using two Protestant samples and assessing perceived support respectively from God, church leaders, and the congregation. Religious support was linked with positive psychological functioning even after controlling for general social support. Given the scale's Christian bias, however (e.g., terms like congregation and church), Fiala and colleagues suggested that the measure should be modified to be more relevant for persons of various faiths.

Three options for such modification are evident: replacing specific Christian terms with similar terms exclusive to others faiths; using generic faithbased language that applies broadly across faiths; and creating whole measures for each faith community. Regarding the first option, replacing Christian terms with another faith's, Lazar and Bjorck (2008) used this approach to assess religious support among a sample of Hebrew-speaking religious Jews living in Israel. They added instructions stating "the term God refers to the supreme power (HKB" H [a Hebrew acronym for The Holy One Blessed Be He], Hashem, Elokim, Creator, Master of the World, etc.)" (p. 408). They also replaced the term church with the concept of religious community because the Jews in this sample lived exclusively in religious neighborhoods, and they replaced the term church leader with relevant words (e.g., rabbi). With these changes, the three-factor structure of the RSS was still replicated, as was the association of religious support and positive psychological functioning above and beyond the effects of social support, suggesting that Fiala and colleagues' model was not unique to Protestants.

Whereas Lazar and Bjorck's (2008) study supports the value of adapting specific versions of the RSS for specific faiths, this approach requires scale modification for each different faith group and does not permit direct quantitative comparison across multiple faiths. Thus, Lazar and Bjorck recommended the second option for scale modification. Specifically they suggested that, "a more generic 'faith-universal' wording might be developed to enable usage of one religious support scale with persons of many faiths" (p. 418).

The third option would be to create separate religious support measures for each religious group. Such a strategy would likely be effective in tapping the cultural depth and particular understanding of each group in question, but any 
attempt to provide universal assessment could lose important information in the process (Hill \& Pargament, 2003).

It seems intuitive that most groups holding common beliefs and/or values (e.g., faith groups) also probably share some level of mutual support among their respective members, and we hypothesized that such support generalizes across many faith traditions. Moreover, using the same measure with multiple groups enables empirical cross-group comparisons and allows for potential identification of common themes. $\dagger$ With this in mind, we used the second option of a multi-faith approach to religious support assessment as a preliminary step.

It may be impossible to create truly faith-universal language, given the tremendous diversity of religious traditions, but feasible to strive for more generic terminology. Faith-generic language might be helpful when attempting to measure a construct relevant to many faiths. To this end, Fiala and colleagues' (2002) three dimensional operational definition of religious support seems useful when considering a variety of faith traditions. Certainly, many religions encourage community, have leaders, and include a God concept. One example is Islam, where group attendance at mosques, leadership by imams, and a clear God concept (Allah) are all central to the faith.

The need for Islamic psychology of religion research is clear. Whereas psychology of religion research in general continues to grow and has more recently begun to diversify, much of this literature has focused on Christians (Gorsuch, 1988; Pargament, 1997; Hill \& Pargament, 2003). In contrast, research with Muslim samples is relatively scarce. For example, a recent PsychInfo search (Sheridan \& North, 2004) covering 105 years using the search terms "Muslim," "Islam," or their derivatives (e.g., "Islamic") revealed only 1,354 abstracts with only $62.5 \%$ summarizing empirical research. For comparison, Maslim and Bjorck (2009) conducted a PsychInfo search using the terms "religious," "religion," or "spiritual" during the same 105 years and found 23,266 abstracts. This paucity of psychology of religion research concerning Muslims is regrettable, especially given that, like never before, Islam has been gaining increased attention in the United States and has been steadily gaining followers. Recent figures estimated between 4-8 million Muslims now live in the U.S. (Mamiya, 2001-2002; Read \& Bartkowski, 2000). Ross-Sheriff (2001) projected that by 2015 Islam will be the second largest religion in the United States.

Even more conspicuous than the lack of research regarding Islam is the lack of research regarding Muslim women. Sheridan and North (2004) found that out of the 1,354 PsycInfo abstracts containing the words Islam, Muslim and/or Moslem, only 5.2\% $(N=70)$ of them covered the topic of women in Islam. It is important to note that religious support might not only be prevalent and valuable for Muslims in general, but for Muslim women in particular. If this were found to be true, such findings would help to counter the common 
negative stereotypical views that "Islam is oppressive to women" (Rehman \& Dziegielewski, 2004, p. 34).

Some recent studies already suggest more positive views. For example, women can view Islam as pragmatically beneficial given its emphasis on the family unit (Mamiya, 2001-2002). In a recent study of 304 women converts to Islam in the United States (Maslim \& Bjorck, 2009), over 92\% choose Islam because they believed that "Islamic (e.g., vs. secular) values are a good fit with my moral and family values" (p. 103). Moreover, contrary to popular misconceptions,

women can also value Islam as a faith which respects women's rights, with its prophet seen as the liberator of women everywhere (e.g., Ahmed, 1992; Mernissi, 1991; Wadud, 1999). For example, some have pointed out that female infanticide was ruled out when Islam was implemented (Douki, Nacef, Belhadj, Bouasker, \& Ghachem, 2003; Sechzer, 2004). Thus, it is perhaps not surprising that both Anway (1996) and Shatzmiller (1996) reported that some women became Muslims because they felt that Islam would protect their rights. Indeed, according to Smith (1999), some converts experience Islam as refreshingly egalitarian, and Maslim and Bjorck found that over $63 \%$ of their sample of 304 Muslim women choose Islam because "I believe it fits well with my cultural views regarding ethnicity and gender" (p. 103). It seems plausible that individuals whose personal views on such factors concur with those espoused by a given faith might perceive that faith as a support resource.

Hill and Pargament (2003) agree with this suggestion, proposing that religion provides a resource of like-minded individuals to assist the believer whenever necessary. Moreover, they noted that religious support from fellow believers provides a "support convoy" (p. 69) that can accompany the individual from birth to death. A qualitative study (Ross-Sheriff, 2001) found this to be true for some immigrant Muslim women, who cited their faith as a source of social support. For such women, the Muslim community presumably can be a haven of familiarity and source of active (emotional, social, and informational) support. Indeed, some African American women who converted to Islam found social support as afforded by their religious community to be helpful in mediating the discrimination they received from greater society (Byng, 1998). Wyche (2004), who also studied African American Muslim women, suggests that "[the] mosque becomes a source of pride, a refuge, and a means of social status in the community, especially when the psychological aspects that build self-esteem are not available in the ... larger society" (p. 326).

Religious support has not only been shown to be derived from relationships with fellow adherents and religious leaders but also from one's perceived relationship with God, at least in Judeo-Christian groups (Fiala, Bjorck, \& Gorsuch, 2002; Lazar \& Bjorck, 2008; Loewenthal, MacLeod, Goldblatt, Lubitsh, \& Valentine, 2000; Maton, 1989). No published quantitative studies have assessed 
the extent to which Muslims perceive Allah as supportive, however. Given that God concepts described by various faiths are diverse, this question clearly merits empirical investigation. For example, various studies have reported that differences in God concept are related to different approaches to coping with stress (e.g., Maynard, Gorsuch, \& Bjorck, 2001; Park \& Cohen, 1993; WongMcDonald \& Gorsuch, 2004). With this in mind, we examined support from Allah, with the hypothesis that Muslims do perceive Allah as supportive.

In summary, we assessed the validity and reliability of the Multi-Faith Religious Support Scale (MFRSS), which is based on the RSS (Fiala et al., 2002). We did so using a sample of Muslim women in the United States, as an example of one important religious group needing increased study. Of course, a multifaith measure should be examined with respect to multiple and diverse faith groups and cultures. Thus, we viewed this as a preliminary validation study. We hypothesized that the three-factor structure of the RSS would be replicated with the MFRSS. We also hypothesized that religious support would function similarly for Muslim women as it has been shown to function for both Christians and Jews. Specifically, we predicted that perceived support from religious leaders, fellow believers, and Allah would all be significantly positively related to emotional functioning. Moreover, we expected the relationship between religious support and emotional functioning to be maintained even after controlling for variance due to general social support.

\section{Method}

\section{Participants}

We used a convenience sample comprised of visitors to the website of a North American Muslim women's magazine. Participants were 539 women ( $M=$ 32.67 years old, $S D=10.37$ years) living in the USA who were Muslims. They identified their ethnic descents as African (33.8\%), Arab (7.2\%), Asian (16.3), Caucasian (23.4\%), Latina (3.9\%), Native-American (1.3\%), or other (unspecified) ethnic descents (14.1\%). This potentially suggests underrepresentation of White and overrepresentation of Black persons, according to recent results by the Pew Research Foundation (2007), which reported Muslim respondents as $38 \%$ White and $26 \%$ Black in a nationwide survey. Participants' family status included $28.8 \%$ single, $59.4 \%$ married, $1.3 \%$ widowed, $9.5 \%$ divorced, and $1.1 \%$ choosing "other." The sample included converts $(57.5 \%)$ and those who had grown up as Muslims (42.5\%), suggesting the magazine is popular with converts (the Pew Research Foundation reports 21\% of the American Muslim population are converts (2007)). Participants were highly educated, completing high school or GED (7.6\%), one year of college (11.3\%), two years of col- 
lege or AA degree (10.6\%), three years of college (7.6\%), four years of college or BA degree $(30.1 \%)$, some graduate school $(12.1 \%)$, or having a graduate degree $(20.8 \%)$. They rated the importance of their religion on a 5-point religious importance scale as high $(M=4.59, S D=.58)$. They had lived in the US an average of 28.04 years $(S D=10.63)$, longer than the period in which they became Muslim $(M=17.66$ years, $S D=10.82)$. On average, they prayed 4.83 times daily on average $(S D=1.68)$, consistent with the Muslim faith's five calls to daily prayer. Also consistent with Muslim theology, every respondent believed in only one God. Most (83.1\%) of the respondents were involved with a Muslim group (e.g., mosque), and most of these groups (85.3\%) had leaders (e.g., imams). Further, most (83.3\%) of the respondents had relationships with their fellow religious participants.

\section{Procedure}

The current research was part of a larger project on Muslim women (e.g., Mas$\lim \&$ Bjorck, 2009). The co-editors of the Muslim women's magazine (circulation $\sim 25,000$ ) were approached with the research proposal. With their permission and cooperation, the research survey was advertised via a link on their website home page, stating, "What does Islam mean to you? Please click here to take a survey. Your voice counts!" Clicking this link connected the reader to another web page with a written endorsement of the research by the magazine editors and a link stating, "Take the survey." Those who clicked this second link were connected to the online survey. It began with an informed consent form clarifying that participation was voluntary and anonymous.

Data entry was instantaneous and continued for three months. According to the magazine editors, the website received 12,000 visitors during this time. Of these, 2,347 clicked the "take a survey" link to read the study's endorsement, and 1008 began the survey (43\% response rate). Of these 1008, 646 reported living in the U.S. A number of these were excluded from the data set, as follows: Eleven reported their gender as male and 15 were not adults (i.e., under 18). Two were dropped because of no belief in God and four because of belief in more than one God-both contrary to central teachings of Islam. Finally, 75 were dropped due to incomplete data. The final sample thus included 539 participants.

\section{Measures}

Religious support. The Multi-Faith Religious Support Scale (MFRSS) was created for this study, based on Fiala and colleagues' (2002) 21-item Religious Support Scale (RSS). The authors reported good factorial validity for the threefactor structure of their measure. The RSS has three parallel 7-item subscales 
respectively assessing perceived support from one's congregation $(>=.91)$, one's church leaders $(>=.90)$, and God $(>=.75)$. Christian language (e.g., "church," "congregation") in the RSS limits its use with other faith groups, however. The MFRSS avoids these limitations, using faith-generic language to assess persons' perceived support respectively from: (a) fellow adherents to their faith, (b) their religious leaders, and (c) their God concept if they have one. In so doing, the MFRSS is intended for potential use with persons of any faith. Instructions begin by explaining the nature of the task as follows:

We also want to learn about how people of different religions really feel about various aspects of their spiritual and religious lives. Religions have different beliefs. For example, some do not believe in God, some believe in one God, and some believe in many Gods, and there are many names used (e.g., Allah, G-d, Jesus, Vishnu, etc.). Some religions have many leaders and some have few. There are many other differences. Please read the following instructions and then answer the questions.

Thereafter, instructions also include definitions of terms as follows:

The word "God" means your idea of God (Supreme Being, Mind, Higher Power, many Gods, etc.) The phrase "religious leaders," means leaders of any religious group where you participate (imams, monks, rabbis, priests, pastors, sunims, small group leaders, etc.). The word "participants" means other regular attenders and/or participants in your religious group (temple, center, synagogue, mosque, church, etc.).

As with the RSS, participants rate 21 statements using a 5-point scale (1= strongly disagree, 5 = strongly agree $)$. They are further instructed to rate an item " 1 " if an item does not apply; e.g., "if you do not believe there is a God, please mark "1" for the items about God."

The MFRSS also begins with five preliminary items, asking whether participants believe in God, more than one God, are part of a religious group, have religious leaders, and/or have relationships with their religious group members. These items are not included when scoring the MFRSS but are used as manipulation checks and/or covariates. Thus, for example, if a person does not believe in God, then ratings of " 1 " on items related to God may be assumed to mean not applicable rather than a strongly disagree regarding support. Conversely, if a person does believe in God, ratings of " 1 " on items related to God presumably do mean strongly disagree.

Based on a focus group discussion with several Muslim adults, the RSS wordings of several items assessing God support were also altered. These modifications were made to address the possibility that some Muslims might be- 
lieve it is presumptuous to assume that one knows Allah's feelings. Thus, the item, "God gives me the sense that I belong" was changed to, "I feel like I belong to God." The item, "I feel appreciated by God" was changed to, "I feel like God appreciates me as His servant." The item, "If something went wrong, God would give me assistance" was changed to, "If something went wrong, I feel like I could ask God for help." The item, "I have worth in the eyes of God" was changed to "I feel like I have worth in the eyes of God." Finally, the item, "God cares about my life and situation" was changed to, "I feel like God cares about my life and situation." It was assumed that these wording changes would be helpful for Muslims while not adversely affecting interpretation by other faith groups, although further studies with other groups will be necessary to test this hypothesis. Psychometrics of the MFRSS are reported in the results section.

Emotional functioning. The same two measures used by Fiala and colleagues (2002) were used in the current study. The 5-item Satisfaction With Life Scale (SWLS; Diener, Emmons, Larsen, \& Griffin, 1985) measures overall subjective well-being. Items are rated on a 7-point scale $(1=$ strongly disagree, 7 $=$ strongly agree) and averaged for a total score between 1 and 7 . The validity of the SWLS is well documented (e.g., Diener et al., 1985; Pavot, Diener, Colvin, Randall, \& Sandvik, 1991). The scale's authors reported good reliability ( $>=$ $.87)$, comparable to that of the current study $(>=.88)$. The Brief Screen for Depression (Hakstian \& McLean, 1989) is a 4-item measure enabling quick assessment of depressive symptoms. It was used here due to its brevity and avoidance of potentially problematic items (e.g., no assessment of suicidality). It is scored by multiplying the score on the first item times four and adding it to the sum of scores from the other three items. The first item asked participants to rate frequency of various depressive symptoms during the last two days, using a 5 -point scale $(1=$ not at all, $5=$ all the time $)$. The remaining three items respectively rate perceived: a) calm versus tension; b) ability to start and complete tasks; and c) satisfaction with ability to perform domestic duties. Each of these three items is rated on a 10-point scale, with 1 representing no depression and 10 representing severe symptoms. Hakstian and McLean report alphas ranging from .63 to .65 , with a 1 -week test-retest correlation of .73. For the current sample, alpha was .76.

Social support. The Multidimensional Scale of Perceived Social Support (MSPSS) is a 12-item measure assessing support from significant other, friends, and family (Zimet, Dahlem, Zimet, \& Farley, 1988). Participants rate agreement with each item $(1=$ very strongly disagree, $7=$ very strongly agree $)$, and item scores are averaged for a total score between 1 and 7 . The scale's authors reported a reliability of $>=.88$. For the current sample, alpha was .91 . This measure was included to enable covariance assessment of religious support above and beyond the effects of general social support. 


\section{Data Analytic Strategy}

There were 75 participants who did not complete the survey but did provide demographic data. Thus, it was possible to compare these 75 with the remaining 539 as a preliminary analysis to assess the representativeness of the 539 . All other analyses only considered the sample $(N=539)$. First, factor analyses were conducted to test the structure of the MFRSS. Next, means and standard deviations were obtained for the variables of interest, followed by zero-order intercorrelations. Then, to facilitate hierarchical canonical analyses and conserve variance, the religious support scales and the two emotional functioning variables were respectively orthogonalized (Gorsuch, 1991). Finally, relationships between religious support and emotional functioning were assessed using hierarchical canonical analyses. These canonical analyses considered the unique effect of each potential relationship, controlling for all other effects (unique variance).

\section{Results}

Preliminary analyses. Some women $(n=75)$ began the survey but did not complete it. The sample $(n=539)$ was compared with these women regarding every demographic variable. There were no significant differences regarding age, years in the United States, ethnicity, family status, years as a Muslim, prayer frequency, or convert status. Compared to the 75 who stopped participating, however, those who completed it were somewhat more educated (with an average of almost four years of college versus almost three), $>=.14, p<.001$ and slightly more spiritual $(M s=4.59$ versus 4.39$),>=.11, p<.01$. A greater percentage of the sample cited religious group participation ( $83 \%$ versus $72 \%$ ), $>2(1)=5.46, p<.05$, and reported relationships with fellow religious participants $(83 \%$ versus $68 \%),>2(1)=10.20, p<.01$. As such, the current sample appears to represent Muslim women who are very well educated and deeply spiritually committed. In addition, they might be over-representative regarding their participation in religious groups and their relationships with fellow group participants.

Factor analyses. Analyses with the UNIMULT (Gorsuch, 1991) statistical package examined the factorial validity of the Multi-Faith Religious Support Scale (MFRSS) with two of the identical factor analyses used by Fiala and colleagues (2002) to develop the original scale. First, exploratory principal factors (using squared multiple correlations as communality estimates with two iterations) were extracted for the number of factors with three unique loadings greater than $|.30|$ (labeled the minimum salient variables criterion by Gorsuch (1983)).These factors were rotated to the Promax (k:4) criterion, initially using 
the Varimax position. This analysis replicated Fiala and colleagues' three-factor structure (see Table 1).

These three factors identified in the exploratory factor analysis were then entered in a confirmatory multiple group factor analysis (CMGFA) to assess how they would function factor-analytically as scales. This technique (Gorsuch, 1983 ) is less widely known than confirmatory factor analysis (CFA) but has been used in multiple studies (e.g., Bjorck \& Kim, 2009; Lazar \& Bjorck, 2008; Fiala et al., 2002; Lucente, Fals-Stewart, Richards, \& Goscha, 2001; Rodenburg \& Fantuzzo, 1993). Gorsuch (1997) noted that, compared to CFA, CMFGA more explicitly links to item analysis. As such, it is especially relevant for scale development because it shows how items function in actual scales rather than

TABLE 1. Exploratory Factor Analysis and Confirmatory Multiple Group Factors ${ }^{a}$

\begin{tabular}{|c|c|c|c|c|c|c|}
\hline \multirow{2}{*}{$\begin{array}{l}\text { Item } \\
\text { Religious leader support }\end{array}$} & \multicolumn{2}{|c|}{ Leader } & \multicolumn{2}{|c|}{ God } & \multicolumn{2}{|c|}{ Participant } \\
\hline & & & & & & \\
\hline 17. My religious leaders give me the sense that I belong. & .91 & .92 & .32 & .31 & .68 & .75 \\
\hline 11. My religious leaders care about my life and situation. & .91 & .92 & .34 & .33 & .66 & .73 \\
\hline 8. I can turn to my religious leaders for advice when I & & & & & & \\
\hline have problems. & .88 & .89 & .29 & .28 & .63 & .71 \\
\hline 20. I feel appreciated by my religious leaders. & .85 & .89 & .34 & .33 & .62 & .68 \\
\hline 5. I am valued by my religious leaders. & .79 & .84 & .36 & .35 & .63 & .68 \\
\hline \multicolumn{7}{|l|}{ 2. If something went wrong, my religious leaders would } \\
\hline give me help. & .80 & .84 & .23 & .23 & .60 & .66 \\
\hline 14. I do not feel close to my religious leaders. & -.73 & -.78 & -.28 & -.27 & -.50 & -.59 \\
\hline \multicolumn{7}{|l|}{ Allah support } \\
\hline 18. God cares about my life and situation. & .26 & .28 & .76 & .78 & .22 & .23 \\
\hline 15. I can turn to God for advice when I have problems. & .21 & .19 & .70 & .70 & .11 & .17 \\
\hline 12. I am valued by God. & .18 & .24 & .64 & .69 & .33 & .26 \\
\hline 9. If something went wrong, God would give me help. & .20 & .17 & .61 & .64 & .05 & .11 \\
\hline 6. I feel appreciated by God. & .16 & .22 & .58 & .65 & .29 & .21 \\
\hline 3. God gives me the sense that I belong. & .26 & .27 & .51 & .63 & .25 & .25 \\
\hline 21. I do not feel close to God. & -.24 & -.26 & -.48 & -.60 & -.22 & -.22 \\
\hline \multicolumn{7}{|l|}{ Participant support } \\
\hline 19. I am valued by other participants in my religious group. & .65 & .69 & .28 & .28 & .87 & .88 \\
\hline $\begin{array}{l}\text { 13. I feel appreciated by other participants in my religious group. } \\
\text { 10. Other participants in my religious group give me the }\end{array}$ & .68 & .70 & .31 & .30 & .84 & .87 \\
\hline sense that I belong. & .70 & .71 & .27 & .27 & .82 & .87 \\
\hline 16. If something went wrong, other participants in my religious & & & & & & \\
\hline group would give me help. & .68 & .69 & .26 & .26 & .81 & .86 \\
\hline 4. Other participants in my religious group care about my life & & & & & & \\
\hline and situation. & .61 & .63 & .21 & .21 & .79 & .84 \\
\hline $\begin{array}{l}\text { 1. I can turn to other participants in my religious group for advice } \\
\text { when I have problems. }\end{array}$ & .61 & .62 & .25 & .25 & .74 & .81 \\
\hline 7. I do not feel close to other participants in my religious group. & -.60 & -.61 & -.25 & -.25 & -.65 & -.75 \\
\hline
\end{tabular}

\footnotetext{
aFactor loadings from the exploratory factor analysis are in regular font; correlations with the factors from the confirmatory multiple group factors analysis are in italics.
} 
in latent variables, which are the focus in CFA. The current CMFGA results also replicated Fiala and colleagues' three-factor solution (see Table 1), with seven parallel items loading highest on each respective factor. The three factors were Religious Leader Support (RLS), God Support, and Religious Participant Support (RPS). Given the Muslim faith of the current sample, God Support will hereafter be referred to as Allah Support (AS).

Religious support subscales (RLS, AS, and RPS) were then created based on the three religious support factors. Specifically, after reverse-scoring negatively worded items, scores on the seven items respectively loading on each of the three factors were averaged, resulting in three scales that each potentially ranged from 1 to 5. Each scale was composed of a parallel set of items (permitting quantitative comparisons). The means and standard deviations for research variables are presented in Table 2 . Reliability estimates for the RLS $(>=.94)$, AS $(>=.77)$, and RPS $(>=.93)$ scales were comparable to those reported by Fiala and colleagues(2002). As in the Religious Support Scale, a Total Religious Support scale $(>=.94)$ can be created by averaging the scores of all 21 items.

Descriptive analyses. Table 2 shows the Cronbach's alpha and descriptive statistics for the criterion variables. The current sample reported moderate to high levels of social support and life satisfaction, as well as all three types of religious support (RLS, AS, and RPS). Regarding depressive symptoms, their levels (Table 2) were slightly more than one standard deviation above the mean reported for a normative group $(M=13.27, S D=5.2$; Hakstian \& McLean, $1989)$ but well below that reported for a depressed group $(M=33.88, S D=$ 6.6).

Correlations. Table 3 shows the zero-order intercorrelations for the variables of interest. Several demographic variables (family status, age, and spiritual importance) were found to correlate with the criterion variables and thus were statistically controlled in the hierarchical canonical analyses (see below). As such, these three demographics were also included in Table 3 with the predictor and criterion variables. All correlations used $r$ except for family status,

TABLE 2. Descriptive Statistics for Criterion Variables

\begin{tabular}{lccccc}
\hline Variable & $\begin{array}{c}\text { Cronbach's } \\
\alpha\end{array}$ & Mean & $\begin{array}{c}\text { Standard } \\
\text { deviation }\end{array}$ & $\begin{array}{c}\text { Potential } \\
\text { range }\end{array}$ & $\begin{array}{c}\text { Actual } \\
\text { range }\end{array}$ \\
\hline Social Support & .91 & 5.70 & 0.98 & $1-7$ & $1.67-7.00$ \\
Leader Support & .94 & 3.74 & 0.91 & $1-5$ & $1.00-5.00$ \\
God Support & .77 & 4.70 & 0.39 & $1-5$ & $2.86-5.00$ \\
Participant Support & .93 & 4.01 & 0.78 & $1-5$ & $1.00-5.00$ \\
Depression & .76 & 19.35 & 8.53 & $7-50$ & $7.00-46.00$ \\
Life Satisfaction & .88 & 4.88 & 1.53 & $1-7$ & $1.00-7.00$ \\
\hline
\end{tabular}


which used $\eta$. This latter statistic is appropriate for examining relationships between nominal and continuous data (Nunnally \& Bernstein, 1994), and posthoc Scheffe tests can then be used to assess specific mean differences. Only married, single, and divorced participants $(N=526)$ were considered when assessing family status, due to the very low numbers of widowed $(N=7)$ and other $(N=6)$ participants. Finally, given the large sample size, the minimum $p$ value was set at .01 to control familywise alpha. The following correlations were significant (see Table 3):

Family status was unsurprisingly related to age, with post hoc Scheffe test (all ps <.01) showing that singles $(M=25.77)$ were younger than married participants $(M=34.56)$, who were younger than divorcees $(M=40.86)$. Family status was related to social support, with post hoc Scheffe test (both $p s<.05$ ) showing that married participants reported more support $(M=5.93)$ than those who were either single $(M=5.60)$ or divorced $(M=5.54)$. Family status also positively correlated with Allah Support, and interestingly, Scheffe test (both $p$ s $<.05$ ) showed that divorced participants reported more Allah support $(M=4.86)$ than either single $(M=4.66)$ or married $(M=4.70)$ participants. Family status was also related to Depression and Life Satisfaction. Scheffe tests (both $p$ s $<.05)$ revealed that singles reported significantly more depressive symptoms $(M=21.91)$ than married participants $(M=18.25)$, and married participants reported more life satisfaction $(M=5.07)$ than singles $(M=4.66)$. Age negatively correlated with depressive symptoms. Spiritual importance and social support were both significantly positively related to all three types of religious support. As in previous studies (Fiala et al., 2002, Lazar \& Bjorck, 2008), the three religious support scales were significantly intercorrelated. Finally, spiritual importance, social support, and all three types of religious sup-

TABLE 3. Correlation Matrix and Alpha Statistics

\begin{tabular}{|c|c|c|c|c|c|c|c|c|c|c|}
\hline Variable & 1. & 2. & 3. & 4. & 5. & 6. & 7. & 8. & 9. & 10. \\
\hline 1. Family status & - & & & & & & & & & \\
\hline 2. Age & $.46^{\star \star}$ & - & & & & & & & & \\
\hline 3. Spirituality & .06 & .07 & - & & & & & & & \\
\hline 4. Prayer frequency & .11 & .07 & $.39 * \star$ & - & & & & & & \\
\hline 5. Social support & $.18^{\star \star}$ & -.04 & $.16^{\star \star}$ & .09 & - & & & & & \\
\hline 6. Leader Support & .10 & .06 & $.29 * \star$ & $.33^{\star *}$ & $.37^{\star \star}$ & - & & & & \\
\hline 7. God support & $.14^{\star \star}$ & .09 & $.39 * *$ & $.29 * *$ & $.26^{\star \star}$ & $.35^{\star *}$ & - & & & \\
\hline 8. Participant support & .09 & .06 & .30 ** & $.35^{\star \star}$ & $.45^{\star \star}$ & $.79^{\star \star}$ & $.32^{\star \star}$ & - & & \\
\hline 9. Depression & $.19^{\star \star}$ & $-.17^{\star \star}$ & $-.17^{\star \star}$ & $-.16^{\star \star}$ & $-.32^{\star \star}$ & $-.27^{\star \star}$ & $-.27^{\star \star}$ & $-.26^{\star \star}$ & - & \\
\hline 10. Life Satisfaction & $.15^{\star}$ & -.04 & $.14^{\star}$ & $.12^{\star}$ & $.42^{\star \star}$ & $.24^{\star \star}$ & $.25 * \star$ & $.24^{\star \star}$ & $-.46^{\star \star}$ & - \\
\hline
\end{tabular}

Note: $N=539$. Note. For family status, only married, single, and divorced participants $(N=526)$ were considered, eliminating the low numbers of widowed $(N=7)$ and other $(N=6)$ participants. Effect size for family status used the statistics eta (?) which is appropriate for nominal variables. All other values use Pearson product moment correlations.

${ }^{\star} p<.05 .{ }^{* *} p<.01 .{ }^{* \star *} p<.001$. 
port were significantly related positively to life satisfaction and negatively to depression.

Orthogonalization. Before conducting hierarchical canonical analyses, the two criteria (Life Satisfaction and Depression) and the three religious support scales (RLS, AS, and RPS) were respectively orthogonalized (Gorsuch, 1991) due to their significant intercorrelations (see Table 3). Orthogonalization allows unique variance to be assessed for all effects while conserving all shared variance. As in previous studies (e.g., Bjorck \& Kim, 2009; Lazar \& Bjorck, 2008; Maynard, Gorsuch, \& Bjorck, 2001), this statistical technique produced strong correlations between the original variables and the corresponding orthogonalized variables (all $r$ s ranging between .88 and .97), supporting these transformations. The orthogonalized versions of RLS, AS, RPS, Depression, and Life Satisfaction were used in the remaining analyses.

Hierarchical canonical analyses. A preliminary analysis tested for the effects of the demographics on the emotional functioning criterion variables. Specifically, family status, age, years in USA, ethnicity, education, spiritual importance, years as a Muslim, prayer frequency, and convert status were entered as a set of predictors, with Depression and Life Satisfaction as the criteria set. This analysis was significant, $F(44,1032)=2.59$, $p<.001$. Univariate post-hoc protected $F$ tests of unique variance revealed that this was due to several findings. Spiritual importance was related to more Life Satisfaction and less Depression, both $F s(1,1032) \geq 3.64, p<.05$. Age was related to more Life Satisfaction, $F(1$, $1032)=4.08, p<.05$. Family status was also related to life satisfaction, $F(1$, $1032)=4.05, p<.001$. Given these findings, spiritual importance, age, and family status were entered first as covariates in the analyses below to control for their effects.

The first analysis (Step 1) entered the three covariates, followed by the set of three religious support scores as the predictor, with Depression and Life Satisfaction as the criterion set. This omnibus analysis was significant, $F(18,1058)$ $=7.32, p<.001$, due to significant multivariate effects of the set of religious support scales on both Depression and Life Satisfaction, both Fs $(3,1058) \geq$ 10.45 , $p s<.001$. Significant univariate analyses revealed that all three religious support scores (RLS, AS, and RPS) were related to less Depression and more Life Satisfaction (Table 4).

The second analysis (Step 2) also entered family status, age, and spiritual importance as covariates. This time, however, social support was entered as a fourth covariate followed by the set of three religious support scores as the predictor, with Depression and Life Satisfaction once again as the criterion set. This omnibus analysis was again significant, $F(20,1056)=7.32, p<.001$, due to significant multivariate effects on both Depression and Life Satisfaction, both Fs $(3,1058) \geq 2.99$, ps $<.05$. Moreover, even after controlling for social support, 
significant univariate analyses revealed that Allah Support (AS) was still significantly related to more Life Satisfaction, and both AS and RLS were related to less Depression (Table 4).

\section{Discussion}

This preliminary validation of the MFRSS provides encouraging empirical support for this measure's construct validity and reliability with respect to all three subscales. Factorial validity was supported with both exploratory and confirmatory multiple group analyses, which replicated the original threefactor structure reported for the RSS (2002). Convergent validity was also supported by the relationships between religious support and emotional functioning discussed below. Moreover, alpha levels for the three respective scales were all comparable to those reported for the RSS. Thus, it appears that the MFRSS demonstrates reliability and validity equal to that of the original RSS. As such, it can serve as an additional tool for use in psychology of religion research. Moreover, the current findings suggest that the MFRSS can be particularly useful when conducting Muslim research, which is beginning to receive the increased careful attention it deserves (Amer \& Hood, 2008).

\section{Allah Support}

Muslim women rated support from Allah highly, and it correlated with more life satisfaction and less depression, as predicted. Moreover, the relationships between support from Allah and both emotional functioning variables remained significant even after controlling for age, spiritual importance, family status, social support, and the other two types of religious support. This

TABLE 4. Hierarchical Canonical Analysis of Religious Support on Depression and Life Satisfaction

\begin{tabular}{|c|c|c|c|c|c|c|c|c|}
\hline \multirow[b]{3}{*}{ Predictor variable } & \multicolumn{4}{|c|}{ Criterion variables: Step 1} & \multicolumn{4}{|c|}{ Criterion variables: Step 2} \\
\hline & \multicolumn{2}{|c|}{ Depression } & \multicolumn{2}{|c|}{ Life satisfaction } & \multicolumn{2}{|c|}{ Depression } & \multicolumn{2}{|c|}{ Life satisfaction } \\
\hline & $\begin{array}{c}\text { Partial } \\
\text { correlation }\end{array}$ & $F$ & $\begin{array}{c}\text { Partial } \\
\text { correlation }\end{array}$ & $F$ & $\begin{array}{c}\text { Partial } \\
\text { correlation }\end{array}$ & $F$ & $\begin{array}{c}\text { Partial } \\
\text { correlation }\end{array}$ & $F$ \\
\hline Social Support & - & - & - & - & -.13 & $10.71^{\star \star}$ & .27 & $44.94^{\star \star \star}$ \\
\hline Leader support & -.13 & $10.21 * \star$ & .11 & $7.36^{\star \star}$ & -.10 & $5.98 * \star$ & .05 & 1.73 \\
\hline God support & -.15 & $13.62^{\star * *}$ & .17 & $16.65^{\star \star \star}$ & -.12 & $8.11^{\star \star}$ & .11 & $7.23^{\star \star}$ \\
\hline Participant support & -.11 & $7.52 \star \star$ & .12 & $8.40 * \star$ & -.04 & 0.86 & .00 & 0.00 \\
\hline
\end{tabular}

Note: In both Step 1 and 2, family status, age, and spiritual importance were entered as covariates, accounting for three degrees of freedom regarding each of the two criteria. For Step 1, only religious support was entered. In Step 2, social support was entered first as a covariate. For each analysis above in Step 1, degrees of freedom =1, 1058. For each in Step 2, degrees of freedom $=1,1056$. All findings reflect unique variance effects, controlling for all other variables.

${ }^{*} p<.05 .{ }^{* *} p<.01{ }^{* * *} p<.001$. 
generally replicates the findings reported for Christians (Fiala et al., 2002) and Jews (Lazar \& Bjorck, 2008) and suggests that Allah's support is experienced as a unique resource for Muslim women. There certainly might be differences regarding God concept for these three faith groups, but it appears all three include the experience of God as truly supportive.

As with the RSS (2002), support from Allah was also positively related to social support. Fiala and colleagues suggested that Christians might view God as a person who provides them such support, given the commonly held Protestant view that God is not only Lord but also a friend. The same might have been true for Muslim women in our sample. It might also be that Muslim women perceive their general social support as a provision from Allah and one way that Allah supports them. Future research should explore these possibilities.

Interestingly, support from Allah was also related to family status, whereby divorced participants reported more support from Allah than either single or married participants. It should first be noted that all three groups reported high levels. Still, the fact that divorced women reported the highest ratings is somewhat surprising, given that divorce is frowned upon in Islam (Badawi, cited in Douki et al., 2003). Perhaps these divorced women felt that their divorces were justifiable exceptions, and cognitive dissonance (Aronson, Blanton, \& Cooper, 1995) prompted them to view Allah as approving and understanding more than fellow Muslims would. Clearly, however, such a tentative explanation requires empirical investigation.

It is noteworthy that the women in our sample rated support from Allah very highly, with higher God support scores than those reported either by Jews (Lazar \& Bjorck, 2008) or Christians (Fiala et al., 2002). This might suggest that Muslim women have a deeper sense of connection with Allah. Alternately, these ratings might have been influenced by the fact that almost 60 percent of the sample were converts, and almost all of these (86\%; Maslim \& Bjorck, 2009) were former Christians. This perhaps led them to feel as though they had moved closer to God by converting to what Islam teaches is the final and true religion. In either case, future research should investigate whether a very high level of Allah support replicates and whether it generalizes to Muslim women outside of the USA.

\section{Religious leader support}

The expected relationship was also found between support from religious leaders and greater life satisfaction and less depression. These effects remained significant after controlling for age, spiritual importance, and family status. In addition, the effect of leader support on depression was maintained even after also controlling for social support, but the effect on life satisfaction was not. These results suggest that leader support might be a more robust resource for 
Muslim women than for Christians because the effect of leader support became nonsignificant for Christians (Fiala et al., 2002) when controlling for social support. Perhaps, Christians tend to view relationships with their religious leaders as being more integrated in (and thus overlapping with) their general social support networks, whereas Muslims might view relationships with their leaders as more unique compared to social relationships in general. In support of this suggestion, a recent study of 102 attenders of 22 mosques in New York City after $9 / 11$ found that, "94\% perceived the imam as a counselor, and $97 \%$ perceived the imam as a source of religious guidance" (Abu-Ras, Gheith, \& Cournos, 2008, p. 15).

The maintained effect of religious leader support regarding depression but not life satisfaction suggest that, for Muslim women, support from leaders might be particularly relevant when facing negative emotional functioning but less so regarding the enhancement of positive functioning. Thus, it appears that Muslim women might perceive support from Allah as a resource in good times and bad but find that support from religious leaders is particularly relevant in harder times.

\section{Religious Participant Support}

Religious participant support was also associated with less depression and more life satisfaction, as hypothesized, and these findings remained after controlling for age, spiritual importance, family status, and the other two types of religious support. The effects became nonsignificant, however, after also controlling for general social support. This is likely due in part to the correlation between participant support and social support, which is not surprising given that both involve resources from other people. It might also suggest that, for Muslim women, support received from fellow participants is not focused only on religious factors and does indeed tend to simply reflect social support in a religious setting (Ventis, 1995). As such, whereas support from fellow believers is clearly a resource, the unique aspects of religious support for Muslim women may be related more to their perceived relationship with Allah and religious leaders. This might also suggest that Muslim women tend to socialize primarily with fellow Muslims, which could render the measurement of support from other believers as somewhat redundant on the measurement of social support. Future research would benefit from assessing this potential overlap between religious and general social networks.

Methodological Limitations.

When interpreting our findings, it should be noted that the cross-sectional design prevents causal interpretations. In addition, the veracity of either the 
participants' responses or identity could not be guaranteed due to the online nature of the data collection. There was no formal publicity for this survey, however, except for the single hyperlink at the magazine website. Thus, only visitors to this website, or those whom these visitors informed, had any knowledge of the survey. Data were also screened for obviously spurious responses (i.e., all positive, all negative, etc.), and none were found. In addition, the magazine website had a successful prior history of hosting other surveys, making it more likely that our data reflected a genuine U.S. sample of Muslim women.

Even so, our findings have generalizability limitations even regarding applicability to other Muslims (e.g., the sample included only women who were highly educated and computer- and internet-savvy). To address the potential educational confound, education level was statistically controlled, and many important findings were still observed. Clearly, samples with broader educational demographics that include both men and women will obviously be required in future studies to address these limitations. The sample also overrepresented both converts and women of African descent, and it underrepresented those of Caucasian descent (Pew Research Center, 2007). Finally, whereas the current study supports the reliability and validity of the MFRSS, research with other faith groups will be needed to support the assertion that this scale is definitely relevant for persons from a variety of other religious traditions. In particular, it will be important to assess groups who do not hold to a personal God concept (e.g., Buddhists), which has been a common thread for all groups studied to date regarding religious support (i.e., Jews, Muslims, and Christians). Still, the current findings for Muslim women, as one important yet understudied religious group, represent a good preliminary step in the validation process.

Despite the limitations, our findings have important ramifications. The MFRSS provides a means to assess religious support within a variety of contexts, permitting the possibility of direct comparisons across faith groups. Hopefully, such studies will provide valuable information regarding the unique ways in which differing groups experience such support. Such insights will also be useful in a variety of religious contexts when considering how religious support interacts with other factors, such as religious coping and general social support. Our findings also provide a preliminary understanding of how religious support functions among Muslim women. Clearly, the women in our sample viewed their faith as a significant source of support from Allah, their religious leaders, and their fellow Muslims. Moreover, their religious support was linked with better emotional functioning, even after controlling for general social support. Together, these findings provide a contradiction to the oversimplified stereotypical assumption that Islam oppresses women. It is our hope that this study will help to facilitate an increasingly more accurate understanding of Islam, particularly within a United States context. 


\section{References}

Amer, M. M., \& Hood, R. W. (2008). Special Issue: Part II. Islamic religiosity: Measures and mental health. Journal of Muslim Mental Health, 3, 1-5.

Anway, C. L. (1996). Daughters of another path: Experiences of American women choosing Islam. Lee's Summit, MO: Yawna.

Aronson, J., Blanton, H., \& Cooper, J. (1995). From dissonance to disidentification: Selectivity in the self-affirmation process. Journal of Personality and Social Psychology, 68, 986-996.

Bjorck, J. P., \& Kim, J. W. (2009). Religious coping, religious support, and psychological functioning among short-term missionaries. Mental Health, Religion, and Culture, $12(7), 611-626$.

Byng, M. D. (1998). Mediating discrimination: Resisting oppression among AfricanAmerican Muslim Women. Social Problems, 45, 473-487.

Diener, E., Emmons, R. A., Larsen, R. J., \& Griffin, S. (1985). The satisfaction with life scale. Journal of Personality Assessment, 49, 71-75.

Douki, S., Nacef, F., Belhadj, A., Bouasker, A., \& Ghachem, R. (2003). Violence against women in Arab and Islamic countries. Archives of Women's Mental Health, 6, 165171.

Fiala, W. E., Bjorck, J. P., \& Gorsuch, R. (2002). The Religious Support Scale: Construction, validation, and cross-validation. American Journal of community Psychology, 30, 761-786.

Gorsuch, R. L. (1983). Factor analysis. City, NJ: Lawrence Erlbaum.

Gorsuch, R. L. (1988). Psychology of religion. Annual Review of Psychology, 39, 201-221.

Gorsuch, R. L. (1991). UniMult for univariate and multivariate data analysis. Altadena, CA: UniMult.

Hakstian, A. R., \& McLean, P. D. (1989). Brief screen for depression. Psychological Assessment, 1, 139-141.

Hill, P. C., \& Pargament, K. I. (2003). Advances in the conceptualization and measurement of religion and spirituality. American Psychologist, 58, 64-74.

Koenig, H. G., McCullough, M. E., \& Larson, D. B. (2001). Handbook of religion and health. New York, NY: Oxford University Press.

Lazar, A., \& Bjorck, J. P. (2008). Religious support and psychosocial well-being among a religious Jewish population. Mental Health, Religion, and Culture, 11(4), 403-421.

Loewenthal, K. M., MacLeod, A. K., Goldblatt, V., Lubitsh, G., \& Valentine, J. D. (2000). Comfort and joy? Religion, cognition, and mood in Protestants and Jews under stress. Cognition and Emotion, 14, 355-374.

Lucente, S. W., Fals-Stewart, W., Richards, H. J., \& Goscha, J. (2001). Factor structure and reliability of the revised Conflict Tactics Scales for incarcerated female substance abusers. Journal of Family Violence, 16, 437-450.

Mamiya, L. H. (2001-2002). Faith-based institutions and family support services among African-American Muslim masjids and Black churches. Journal of the Interdenominational Theological Center, 29, 25-61.

Maslim, A. A., \& Bjorck, J. P. (2009). Reasons for conversion to Islam among women in the United States. Psychology of Religion and Spirituality, 1, 97-111.

Maton, K. I. (1989). The stress-buffering role of spiritual support: Cross-sectional and prospective investigations. Journal for the Scientific Study of Religion, 28, 310-323. 
Maynard, E. A., Gorsuch, R. L., \& Bjorck, J. P. (2001). Religious coping style, concept of God, and personal religious variables in threat, loss, and challenge situations. Journal for the Scientific for the Scientific Study of Religion, 40 (1), 65-74.

Mernissi, F. (1991). The veil and the male elite: A feminist interpretation of women's rights in Islam. Reading, MA: Addison-Wesley Pub.

Nunnally, J. C., \& Bernstein, I. (1994). Psychometric Theory (3rd ed.). New York: McGraw-Hill.

Pargament, K. I. (1997). The psychology of religion and coping: Theory, research, and practice. New York: Guilford Press.

Park, C. L., \& Cohen, L. (1993). Religious and non-religious coping with the death of a friend. Cognitive Therapy and Research, 17, 561-577.

Pavot, W. G., Diener, E., Colvin, C. R., \& Sandvik, E. (1991). Further validation of the SWL Scale: Evidence for the cross-method convergence of well-being measures. Journal of Personality Assessment, 57, 149-161.

Pew Research Center (2007). American Muslims: Middle class and mostly mainstream. Retrieved January 12, 2011 from http://pewresearch.org/assets/pdf/muslim-americans.pdf.

Read, J. G., \& Bartkowski, J. P. (2000). To veil or not to veil? A case study of identity negotiation among Muslim women in Austin, Texas. Gender and Society, 14, 395-417.

Rehman, T. F., \& Dziegielewski, S. F. (2004). Women who choose Islam: Issues, changes and challenges in providing ethnic-diverse practice. International Journal of Mental Health, 32, 31-49.

Rodenburg, F. A., \& Fantuzzo, J. W. (1993). The measure of wife abuse: Steps toward the development of a comprehensive assessment technique. Journal of Family Violence, 8, 203-228

Ross-Sheriff, F. (2001). Immigrant Muslim women in the United States: Adaptation to American society. Journal of Social Work Research, 2, 283-294.

Sechzer, J. A. (2004). "Islam and Woman: Where Tradition Meets Modernity": History and interpretations of Islamic Women's Status. Sex Roles, 51, 263-272.

Shatzmiller, M. (1996). Marriage, family, and the faith: Women's conversion to Islam. Journal of Family History, 21, 235-266.

Sheridan, L. P., \& North, A. C. (2004). Representations of Islam and Muslims in psychological publications. International Journal for the Psychology of Religion, 14(3), 149-159.

Smith, J. I. (1999). Islam in America. New York: Columbia University Press.

Ventis, W. L. (1995). The relationships between religion and mental health. Journal of Social Issues, 51, 33-48.

Wadud, A. (1999). Qur'an and woman: Rereading the sacred text from a woman's perspective. New York: Oxford University Press.

Wong-McDonald, A., \& Gorsuch, R. L. (2004). A multivariate theory of God concept, religious motivation, locus of control, coping, and spiritual well-being. Journal of Psychology and Theology, 32, 318-334

Wyche, K. F. (2004). African American Muslim women: An invisible group. Sex Roles, 51, 319-328.

Zimet, G. D., Dahlem, N. W., Zimet, S. G., \& Farley, G. K. (1988). The multidimensional scale of perceived social support. Journal of Personality Assessment, 52, 30-41. 